\title{
Metodologia de infecção experimental e grau de susceptibilidade do híbrido "tambacu" e Leporinus macrocephalus Garavello \& Britski (Osteichthyes, Anostomidae) a quatro inóculos de trofozoítos de Icthyophthirius multifiliis Fouquet (Protozoa, Ciliophora)
}

\author{
Valéria Nogueira de Souza ${ }^{1}$ \\ Maurício Laterça Martins ${ }^{1,3}$ \\ Flávio Ruas de Moraes 1, 2,3 \\ Sérgio do Nascimento Kronka ${ }^{4}$
}

\begin{abstract}
Methodology of experimental infection and the susceptibility degree of the tambacu hybrid and Leporinus macrocephalus Garavello \& Britski to four inocula of trophonts of Ichtyophthirius multifiliis Fouquet. Tropical fishes like Leporinus macrocephalus Garavello \& Britski, 1988 ("piauçu") and the hybrid "tambacu" (Piaractus mesopotamicus Holmberg, 1887 "pacu" male x Colossoma macroponum Cuvier, 1818 "tambaqui" female) were experimentally infected with four inocula of trophonts of Ichthyophthirius multifiliis Fouquet, 1876 (Protozoa, Ciliophora) and the infection level was evaluated. Each one of twelve experimental units consisted of a tank with 200 liters of water and two specimens of each kind of fish. The following treatments were designed to each tank, in triplicate: 8, 16, 32 and 64 trophonts. After 8 days of exposure the fishes were killed and the number of trophonts was counted at a stereoscopic microscope. This assay showed to be feasible at tropical conditions and was able to show that "tambacu" was more susceptible than "piauçu". KEY WORDS. Ichthyophthirius multifiliis, tropical fish, experimental infection, susceptibility
\end{abstract}

Ichtyophthirius multifiliis Fouquet, 1876 (Protozoa, Ciliophora) é um ectoparasito que penetra completamente na epiderme de peixes de água doce e alimenta-se de células do hospedeiro, o qual geralmente sucumbe às condições patológicas da infecção (KUDO 1966).

Para a infecção experimental o parasito I. multifiliis deve ser cultivado, necessitando de passagens sucessivas na espécie de hospedeiro escolhido. A manutenção do parasito em laboratório implica em certas dificuldades já que as diferentes fases do seu ciclo de vida podem ser afetadas por condições desfavoráveis da água, pela imunidade ou pela morte do hospedeiro (DICKERSON et al. 1985).

1) Centro de Aqüicultura, Universidade Estadual Paulista. Rodovia Prof. Paulo Donato Castellani, Km 5, 14870-000 Jaboticabal, São Paulo, Brasil.

2) Departamento de Patologia Veterinária, Universidade Estadual Paulista. Rodovia Prof. Paulo Donato Castellani, Km 5, 14870-000 Jaboticabal, São Paulo, Brasil.

3) Centro de Pesquisas em Sanidade Animal, CPPAR-UNESP. Rodovia Prof. Paulo Donato Castellani, km 5, 14870-000 Jaboticabal, São Paulo, Brasil.

4) Departamento de Ciências Exatas, Universidade Estadual Paulista. Rodovia Prof. Paulo Donato Castellani, km 5, 14870-000 Jaboticabal, São Paulo, Brasil.

Correspondência: Flávio Ruas de Moraes. E-mail: fruas@fcav.unesp.br

Revta bras. Zool. 18 (3): 803 - 811, 2001 
Há dificuldades metodológicas para a infecção experimental pois, segundo dados não publicados deste laboratório, as respostas de peixes tropicais ao parasito parecem ser diferentes daquelas descritas na literatura para peixes de clima temperado.

Este ensaio avaliou o método de infecção experimental, com quatro inóculos contendo quantidades crescentes de trofozoitos do parasito Ichthyophthirius multifiliis Fouquet, 1876 e os graus de susceptibilidade de Leporinus macrocephalus Garavello \& Britski, 1988 ("piauçu") (Osteichthyes, Anostomidae) e do híbrido "tambacu" (Piaractus mesopotamicus Holmberg, 1887 "pacu" macho x Colossoma macropomum Cuvier, 1818 "tambaqui" fềmea) (Osteichthyes, Characidae) a cada um dos inóculos. A escolha desses peixes deveu-se à posição de destaque que ocupam na preferência dos criadores.

\section{MATERIAL E MÉTODOS}

O experimento foi realizado no Centro de Pesquisas em Sanidade Animal (CPPAR), Universidade Estadual Paulista (UNESP), Jaboticabal, São Paulo, durante agosto de 1998 e reproduzido em setembro do mesmo ano. As referências a estes ensaios estão aqui descritas, respectivamente, como "primeiro" e "segundo" experimentos. Quando não houver este tipo de referência, significa que as condições foram as mesmas em ambos os casos.

O objetivo visou à infecção experimental de 24 L. macrocephalus e de 24 híbridos "tambacu" com a inoculação de trofozoítos do protozoário I. multifiliis na água, tanto no primeiro como no segundo ensaio. Para isso adotou-se o delineamento inteiramente casualizado com parcelas subdivididas e três repetições. As parcelas foram compostas por 12 aquários que continham 220 litros de água. Nelas foram inicialmente casualizadas as diferentes quantidades de trofozoítos a serem inoculadas, $\mathrm{P} 1, \mathrm{P} 2, \mathrm{P} 3$ e P4, que constituíram os tratamentos principais (P) com, respectivamente, $8,16,32$ e 64 trofozoítos por aquário ou $2,4,8$ e 16 trofozoítos por peixe. Cada parcela foi subdividida em duas subparcelas, em que foram casualizados os tratamentos secundários (S) formados por dois espécimes de "tambacu" (S1) e dois de "piauçu" (S2). Os tratamentos foram formados pela combinação entre principais e secundários e estão expostos na tabela I.

Tabela I. Tratamentos formados pela combinação entre os diferentes níveis de tratamentos principais $(P)$ e secundários $(S)$.

\begin{tabular}{|c|c|c|c|c|}
\hline \multirow{2}{*}{ Peixe (S) } & \multicolumn{4}{|c|}{ Número de trofozoitos por aquário $(P)$} \\
\hline & $8(\mathrm{P} 1)$ & $16(\mathrm{P} 2)$ & $32(\mathrm{P} 3)$ & $64(\mathrm{P} 4)$ \\
\hline Tambacu (S1) & P1 S1 & P2 S1 & P3 S1 & P4 S1 \\
\hline Piauçu (S2) & P1S1 & P2 S2 & P3 S2 & P4 S2 \\
\hline
\end{tabular}

Para a escolha dos números de trofozoítos de cada inóculo, tomou-se como referencial cinco trofozoítos por peixe, número utilizado por AREERAT (1974 apud DICKERSON et al. 1981) para infectar "bagres do canal".

Os dados obtidos à necropsia foram transformados em $\sqrt{\mathrm{x}+0,5} \mathrm{e}$ a análise estatística foi feita de acordo com o delineamento inteiramente casualizado, com 
parcelas subdivididas (STEEL \& TORRIE 1980), para comparar a diferença entre os números totais de trofozoítos encontrados em "tambacus" e "piauçus", empregando-se o nível de significância de $5 \%$.

O parasito I. multifiliis foi inicialmente obtido de um "caboja", Hoplosternum littorale Hancock, 1828 (Siluriformes, Callichthydae) altamente infectado e, a partir dele, repicado em "tambacus" e "tambaquis", todos mantidos em aquários providos de aeração artificial. A repicagem baseou-se na colocação de peixes sadios em aquários onde havia peixes contaminados, de acordo com metodologia descrita por EWING et al. (1982).

Os peixes experimentalmente desafiados, 24 alevinos de "tambacus" e o mesmo número de alevinos de "piauçus", foram obtidos em piscicultura comercial - Piscicultura "Talarico" (Tabatinga, São Paulo) e no Centro de Aqüicultura, UNESP (Jaboticabal, São Paulo).

Antes de se proceder à exposição dos peixes ao protozoário, os animais foram tratados e examinados para a presença de parasitos. Apenas quando o exame parasitológico resultou negativo iniciou-se o experimento propriamente dito.

Para obter os trofozoítos a que os peixes seriam expostos, no primeiro experimento, um "tambacu" adulto e no segundo, alevinos de "tambaquis", todos altamente infectados foram postos em pouca água durante aproximadamente meia hora e depois retirados. Os parasitos que haviam sido deles desalojados, foram colhidos aos poucos com pipeta de Pasteur (PYLE \& DAWE 1985, ligeiramente modificada), colocados em placa de Petri e levados ao estereomicroscópio para a colheita individual dos trofozoítos. Uma vez colhidos foram transferidos para pequenas placas de Petri de acordo com o número a ser adicionado ao aquário. Antes de ser posto nessas placas, cada trofozoíto foi observado ao microscópio, em lâmina histológica (sem lamínula), para observação da integridade de sua membrana e de sua motilidade.

Para evitar que os trofozoítos ficassem aderidos às placas e assim não fossem expostos aos peixes, cada placa com o devido número de trofozoítos foi mergulhada no aquário adequado e aí permaneceu durante todo o período experimental (oito dias). Neste período, os peixes receberam de 1 a $3 \mathrm{~g}$ de ração extrusada, por aquário, uma vez ao dia. $\mathrm{O}$ excesso foi retirado com peneira alguns minutos após a oferta.

Passados oito dias após a inoculação os peixes foram colhidos com puçá, sacrificados, medidos e pesados. Em seguida, foram examinados para a contagem de trofozoítos ao estereomicroscópio, em três arcos branquiais colhidos ao acaso, nas nadadeiras caudal, anal, dorsal, peitoral (esquerda e direita) e pélvica (esquerda e direita) e no muco do corpo, raspado da abertura do opérculo à base da nadadeira caudal de ambos os lados.

\section{RESULTADOS}

\section{Primeiro experimento}

Os "tambacus" apresentaram comprimento padrão médio de $12,64 \pm 1,02 \mathrm{~cm}$ e peso médio de $58,56 \pm 14,18 \mathrm{~g}$ e os "piauçus", $13,73 \pm 1,27 \mathrm{~cm}$ e $55,77 \pm 14,20 \mathrm{~g}$, respectivamente. 
Dos 24 "tambacus" (S1) expostos ao parasito, todos estavam parasitados em uma ou mais regiões examinadas (100\%). Dos 24 "piauçus" (S2) desafiados, cinco apresentaram o parasito à necropsia, correspondendo à 33,3\% de prevalência.

O número de trofozoítos encontrados por região examinada em "tambacus" e "piauçus", neste experimento, estão expressos nas tabelas II e III.

Tabela II. Totais de trofozoítos encontrados por região examinada em "tambacus" $(n=6)$ em função do número de trofozoítos inoculados nos primeiro e segundo experimentos.

\begin{tabular}{|c|c|c|c|c|c|c|c|c|}
\hline \multirow[t]{3}{*}{ Região examinada } & \multicolumn{8}{|c|}{ Número de trofozoitos inoculados } \\
\hline & \multicolumn{4}{|c|}{ Primeiro experimento } & \multicolumn{4}{|c|}{ Segundo experimento } \\
\hline & P1 (8) & P2 (16) & P3 (32) & P4 (64) & P1 (8) & P2 (16) & P3 (32) & P4 (64) \\
\hline Muco & 63 & 230 & 195 & 680 & 308 & 78 & 102 & 200 \\
\hline Nadadeira caudal & 7 & 69 & 40 & 212 & 41 & 15 & 25 & 40 \\
\hline Nadadeira anal & 16 & 48 & 48 & 170 & 25 & 4 & 16 & 29 \\
\hline Nadadeira peitoral direita & 6 & 37 & 12 & 72 & 41 & 15 & 26 & 9 \\
\hline Nadadeira ventral direita & 0 & 9 & 8 & 21 & 11 & 5 & 10 & 9 \\
\hline Nadadeira dorsal & 8 & 57 & 52 & 260 & 30 & 17 & 36 & 28 \\
\hline Nadadeira peitoral esquerda & 4 & 24 & 16 & 69 & 32 & 12 & 28 & 15 \\
\hline Nadadeira ventral esquerda & 0 & 8 & 6 & 16 & 2 & 5 & 36 & 8 \\
\hline (3) arcos branquiais & 0 & 20 & 54 & 174 & 2 & 0 & 0 & 2 \\
\hline Total por inóculo & 104 & 502 & 431 & 1674 & 492 & 151 & 279 & 340 \\
\hline
\end{tabular}

Tabela III. Totais de trofozoítos encontrados por região examinada em "piauçus" $(n=6)$ em função do número de trofozoítos inoculados nos primeiro e segundo experimentos.

\begin{tabular}{|c|c|c|c|c|c|c|c|c|}
\hline \multirow{3}{*}{ Regiāo examinada } & \multicolumn{8}{|c|}{ Número de trofozoitos inoculados } \\
\hline & \multicolumn{4}{|c|}{ Primeiro experimento } & \multicolumn{4}{|c|}{ Segundo experimento } \\
\hline & $\mathrm{P} 1(8)$ & P2 (16) & P3 (32) & P4 (64) & P1 (8) & P2 (16) & P3 (32) & P4 (64) \\
\hline Muco & 1 & 1 & 2 & 1 & 0 & 0 & 0 & 0 \\
\hline Nadadeira caudal & 0 & 0 & 0 & 0 & 0 & 0 & 0 & 0 \\
\hline Nadadeira anal & 0 & 1 & 0 & 0 & 0 & 0 & 0 & 0 \\
\hline Nadadeira peitoral direita & 0 & 1 & 0 & 0 & 0 & 1 & 1 & 1 \\
\hline Nadadeira ventral direita & 0 & 0 & 0 & 0 & 0 & 0 & 0 & 0 \\
\hline Nadadeira dorsal & 0 & 3 & 4 & 0 & 2 & 0 & 0 & 0 \\
\hline Nadadeira peitoral esquerda & 0 & 1 & 0 & 0 & 1 & 0 & 0 & 0 \\
\hline Nadadeira ventral esquerda & 0 & 0 & 0 & 0 & 0 & 0 & 0 & 0 \\
\hline (3) arcos branquiais & 0 & 0 & 0 & 6 & 0 & 0 & 0 & 0 \\
\hline Total por inóculo & 1 & 7 & 6 & 7 & 3 & 1 & 1 & 1 \\
\hline
\end{tabular}

\section{Segundo experimento}

Os "tambacus" apresentaram comprimento padrão médio de 10,30 $\pm 0,73 \mathrm{~cm}$ e peso médio de $34,52 \pm 6,52 \mathrm{~g}$ e os "piauçus", $10,42 \pm 0,90 \mathrm{~cm}$ e 22,23 $\pm 4,79 \mathrm{~g}$, respectivamente.

Dos 24 "tambacus" desafiados, apenas dois espécimes do aquário onde foi colocada a segunda repetição do inóculo P4 (64 trofozoítos) apresentaram-se negativos quanto à presença do parasito em pelo menos uma das regiões examinadas 
à necropsia. Com isso, a prevalência do parasito foi da ordem de $91.7 \%$ em "tambacus". Quanto aos "piauçus", um espécime do aquário com a primeira repetição do inóculo $\mathrm{P} 4$ foi perdido no dia seguinte à inoculação dos trofozoítos na água. Dentre os 23 espécimes de "piauçus" então expostos ao parasito, cinco apresentaram um ou dois trofozoítos em pelo menos uma das regiões examinadas, resultando na prevalência de $21,7 \%$.

O número de trofozoítos encontrados por região examinada em "tambacus" e "piauçus", no segundo experimento estão expressos tabelas II e III.

Em ambos os experimentos, a quantidade de trofozoítos encontrada no muco raspado da superfície do corpo de "tambacus" foi a mais numerosa, para quaisquer inóculos, porém, nem sempre correspondeu ao número de trofozoítos inoculados. No primeiro experimento, a inoculação de 64 trofozoítos/aquário (P4) resultou na maior prevalência (680 trofozoítos) e a inoculação de oito trofozoítos/aquário (P1) resultou na menor. Porém, no segundo experimento, não ocorreu essa relação proporcional entre os inóculos e os níveis de parasitose obtidos: a inoculação de P4 resultou em 200 trofozoítos no muco e a de P1, em 308. Vale ressaltar que a quantidade de muco raspada de todos os "tambacus" foi muito maior que a obtida com a raspagem dos "piauçus".

Outras duas regiões de destaque quanto ao número de trofozoítos encontrados à necropsia foram as nadadeiras caudal e dorsal dos "tambacus". Em ordem decrescente do número de trofozoítos obtidos, em função de todos os inóculos, no primeiro experimento, a nadadeira dorsal ficou em segundo lugar, com 377 trofozoítos e a caudal, em terceiro, com 328 trofozoítos. No segundo experimento, a nadadeira caudal ficou em segundo lugar, com 121 trofozoítos e a dorsal, em terceiro com 111. Também em relação a essas nadadeiras, não foi observada correlação entre o tamanho do inóculo e o número de trofozoítos obtidos.

As demais nadadeiras apresentaram números variáveis de trofozoítos e a seqüência das mais infectadas para as menos não foi a mesma nos dois experimentos.

O número de trofozoítos presentes nos arcos branquiais de "tambacus" se destacou pela grande variação de um experimento para o outro. No primeiro experimento, esse número foi crescente de acordo com o aumento do número de trofozoítos inoculados e resultou no total de 248 trofozoitos, sendo 174 devidos à inoculação de 64 trofozoítos/aquário (P4). No segundo, da inoculação de $16(\mathrm{P} 2)$ e 32 (P3) trofozoítos/aquário não resultou nenhum trofozoíto e da inoculação de oito (P1) e 64 (P4) trofozoítos/aquário resultou o total de quatro trofozoítos, dois para cada inóculo.

Com relação aos "piauçus", no primeiro experimento, de 21 trofozoítos neles encontrados, cinco localizavam-se no muco, sete na nadadeira dorsal e seis, nos arcos branquiais examinados. No segundo experimento, foram encontrados ao todo seis trofozoítos, sendo que três estavam na nadadeira peitoral direita, dois, na nadadeira dorsal e um na nadadeira peitoral esquerda.

O número de trofozoítos de todos os peixes e regiões examinadas foi comparado estatisticamente, dentro de cada experimento, para verificar se houve diferença significativa entre os efeitos dos diferentes números de trofozoitos inocu- 
lados sobre o número de trofozoítos recuperados e também se houve diferença significativa entre as prevalências entre "tambacus" e "piauçus". A tabela IV mostra o resultado dos testes de comparação de médias das cargas parasitárias do primeiro experimento e a tabela $\mathrm{V}$, os resultados do segundo.

Tabela IV. Primeiro experimento - médias de infecção comparadas pelo teste de Tukey (5\%). Em cada linha compara-se tratamentos principais dentro de cada tratamento secundário (letras minúsculas) e em cada coluna compara-se tratamentos secundários dentro de cada um dos niveis do tratamento principal (letras maiúsculas).

\begin{tabular}{ccccc}
\hline Causas de variação & $\mathrm{P} 1$ & $\mathrm{P} 2$ & $\mathrm{P} 3$ & $\mathrm{P} 4$ \\
\hline $\mathrm{S} 1$ & $4,0330 \mathrm{~A} \mathrm{~b}$ & $8,7137 \mathrm{~A} \mathrm{~b}$ & $8,0498 \mathrm{~A} \mathrm{~b}$ & $16,2095 \mathrm{~A} \mathrm{a}$ \\
$\mathrm{S} 2$ & $0,8047 \mathrm{~A} \mathrm{a}$ & $1,1926 \mathrm{~B} \mathrm{a}$ & $1,1785 \mathrm{~B} \mathrm{a}$ & $1,3307 \mathrm{~B} \mathrm{a}$ \\
\hline
\end{tabular}

Diferenças mínimas significativas: para comparação nas linhas (tratamentos principais dentro de cada tratamento secundário): 6,0656; para comparação nas colunas (tratamentos secundários dentro de cada tratamento principal): 4,3194.

Tabela V. Teste de Tukey (5\%) para tratamentos principais e secundários.

\begin{tabular}{cccccc}
\hline & \multicolumn{2}{c}{ Tratamento principal } & & \multicolumn{2}{c}{ Tratamento secundário } \\
\cline { 2 - 3 } & Tratamento & Média & & Tratamento & Média \\
\hline & P1 & $4,8223 \mathrm{~A}$ & & S1 & 6,3318 a \\
Diferença minima significativa & P3 & $3,5236 \mathrm{~A}$ & & S2 & $0,8479 \mathrm{~b}$ \\
& $\mathrm{P} 4$ & $2,3309 \mathrm{~A}$ & & \\
\hline
\end{tabular}

No primeiro experimento, o efeito do número de trofozoítos inoculados sobre o número de trofozoítos recolhidos oito dias após a inoculação na água dependeram da espécie de peixe, o que não ocorreu no segundo experimento. Assim, no primeiro caso, nos "tambacus" (S1), o inóculo de 64 trofozoítos por aquário resultou em maior média de carga parasitária, seguido pelos inóculos de 16, 32 e 8, de acordo com a ordem decrescente das respectivas médias de prevalência, que não diferiram entre si. Entre os "piauçus" não houve diferença significativa entre as médias de infecção obtidas com as diferentes quantidades de trofozoítos inoculados. No segundo experimento, em que o efeito do número de trofozoítos inoculados sobre o número de trofozoítos observados oito dias após a inoculação não dependeram da espécie de peixe, não houve diferença significativa entre os diferentes inóculos. Nesse caso, as médias obtidas, em ordem decrescente, foram resultantes da inoculação de 8, 64, 32 e 16 trofozoítos por aquário.

No primeiro experimento, a interação entre "número de trofozoítos/aquário" e "tipos de peixe" foi significativa $(\alpha=5 \%)$ indicando que existe dependência entre os efeitos desses fatores e por isso, os graus de liberdade dessa interação foram desdobrados. Quando o número de trofozoítos/aquário foi igual a 8(P1), não houve diferença significativa $(\alpha=5 \%)$ entre os números de trofozoítos encontrados em "tambacus" (S1) e "piauçus" (S2). Para 16 (P2), 32 (P3) e 64 (P4) trofozoítos/aquário observou-se 
diferença significativa $(\alpha=1 \%)$ nos números de trofozoitos encontrados em "tambacus" (S1) e "piauçus"(S2). As médias dos números de trofozoítos encontrados foram maiores em "tambacus" nas três doses de inóculo (Tab. IV). O efeito das diferentes quantidades de trofozoítos por aquário $(8,16,32$ e 64$)$ sobre o número de trofozoitos encontrados diferiram significativamente entre si apenas no caso dos "tambacus" (S1). Segundo o teste de Tukey (5\%) (Tab. IV) para médias de tratamentos principais dentro do tratamento S1, a dose P4 (64 trofozoítos/aquário) diferiu significativamente das demais e estas não diferiram significativamente entre si.

No segundo experimento a interação entre "número de trofozoítos/aquário" e "tipos de peixe" não foi significativa $(\alpha=5 \%)$ indicando que não existiu dependência entre os efeitos desses fatores. Não houve diferença significativa $(\alpha=$ $5 \%)$ entre os efeitos das diferentes quantidades de trofozoítos por aquário $(8,16,32$ e 64) sobre o número de trofozoítos encontrados em "tambacus" e "piauçus" (Tab. V). Quanto aos efeitos dos tipos de peixes, houve diferença significativa $(\alpha=5 \%)$ entre o número de trofozoítos observados em "tambacus" e "piauçus". Neste caso, tambacus foram os que apresentaram a maior média (Tab. V).

\section{DISCUSSÃO}

A metodologia utilizada teve como base a utilização de trofozoítos de $I$. multifiliis para provocar a infecção experimental, como mostrou ser possivel AREERAT (1974 apud DiCKERSON et al. 1981) e foi relatado por DiCKERSON et al. (1985) e utilizado por EWING et al. (1982). Explicou-se, no presente estudo, a preferência por trofozoítos ao invés de terontes devido a tentativas anteriores mal sucedidas que, resumidamente, referiram-se à obtenção de terontes em número insuficiente e à contaminação desses por outros parasitos, o que inviabilizava a infecção.

A introdução de peixes contaminados em pequeno volume de água durante meia hora para logo em seguida colher com pipeta os trofozoítos liberados, conforme metodologia proposta por PYLE \& DAWE (1985) pareceu ser a melhor opção.

A escolha dos tamanhos dos inóculos foi baseada nos relatos de DICKERSON et al. (1981), segundo os quais, AREERAT (1974) em infecção experimental com 20 trofozoítos por aquário contendo cinco Ictalurus punctatus (Siluriformes, Ictaluridae) não imunes (quatro trofozoitos por peixe) obteve como resultado a morte de todos os peixes sete dias após a infecção. As quantidades de trofozoítos aqui testadas $(8,16,32$ e 64 trofozoítos/aquário) não provocaram a morte de nenhum dos animais até oito dias depois. Quando os peixes são obtidos de piscicultura comercial, a possibilidade de alguns deles já terem sido expostos ao parasito não pode ser excluída (MCCALLUM 1986). Assim, a avaliação da prevalência deve levar em conta o contato prévio dos peixes com alguma forma do protozoário.

Desde que com a exposição dos peixes a trofozoítos torna difícil a determinação da quantidade exata de parasitos a que os peixes são desafiados, as diferenças obtidas na avaliação da carga parasitária podem refletir variação na resistência dos peixes aos parasitos ou simplesmente variação no número de parasitos a que os peixes foram expostos (CLAYTON \& PRICE 1988). Estudando a resistência a infecções experimentais com I. multifiliis, CLAYTON \& PRICE (1994) relataram que os 
níveis de infecção foram significativamente influenciados pela área corporal e pelo tempo de infecção. No caso em questão, o tempo de exposição ao parasito foi o mesmo para todos os peixes, mas a diferença de área corporal entre "piauçus" e "tambacus", que é real, não foi levada em consideração. Embora não tenha havido padronização à resposta por área, como seria ideal segundo CLAYTON \& PRICE (1988), os resultados não deixaram dúvidas quanto à maior susceptibilidade de "tambacus" em relação a "piauçus" frente ao parasito.

Com respeito ao que foi citado sobre hibridação, deve-se lembrar que o "tambacu", cujos níveis de infecção foram maiores que os de "piauçus", é híbrido de P. mesopotamicus ("pacu") e C. macropomum ("tambaqui"), mas o tipo de hibridação feito nesse caso, como na maioria deles, de acordo com CLAYTON \& PRICE (1994), concentrou-se na melhoria de aspectos zootécnicos como ganho de peso, conversão alimentar e percentual de gordura, sem levar em consideração a susceptibilidade à doenças. Embora, Chevassus \& PETiT (1975) e Chevassus et al. (1983) (apud CHEvassus \& DORSON 1990), tenham observado que híbridos sejam tão susceptíveis a doenças quanto as espécies parentais. em estudo sobre a susceptibilidade de "pacus", "tambaquis", "tambacus" e "carpas" criados em sistema intensivo aos parasitos mixosporídeos (Myxozoa: Myxobolidae), em ordem decrescente de ocorrência é de 97,3\% em "pacus", 33\% em "tambacus", 5,6\% em "tambaquis" e $0,0 \%$ em "carpas", ficando constatanda a susceptibilidade intermediária dos "tambacus" em relação às espécies parentais (MARTINS et al. 1999).

\section{CONCLUSÕES}

A metodologia utilizada, baseada na literatura internacional, é viável para infecção experimental com I. multifiliis em peixes tropicais e defende-se o uso de trofozoítos em lugar de terontes do parasito, mesmo havendo variabilidade de informações a respeito do número de terontes liberados por trofozoito.

"Tambacus" foram mais susceptiveis ao parasito que "piauçus" favorecendo sua multiplicação com tendência ao aumento da tensão ambiental de infecção em tanques contaminados.

\section{REFERÊNCIAS BIBLIOGRÁFICAS}

Chevassus, B. \& M. Dorson. 1990. Genetics of resistance to disease in fishes. Aquaculture 85: 83-107.

Cl.ayton, G.M. \& D.J. Price. 1988. Ichthyophthirius multifiliis: standardization of the infectionresponse model in Ameca splendens (Miller \& Fitzsimons). Jour. Fish Dis. 11: 371-377.

1994. Heterosis in resistance to Ichthyophthirius multifiliis infections in poeciliid fish. Jour. Fish Biol. 44: 59-66.

Dickerson, H.W.; D.L. Dawe; J.B. Gratzek; J. Brown \& S.W. PyLE. 1981. Induction of Ichthyophthirius multifiliis Fouquet infections in channel catfish, Ictalurus punctatus Rafinesque: standardization of the procedure. Dev. Biol. Stand. 49: 331-336.

Dickerson, H.W.; A.L. LOHR \& J.B. GrATZEK. 1985, Experimental intraperitoneal infection of channel catfish Ictalurus punctatus (Rafinesque), with Ichthyophthirius multifiliis (Fouquet). Jour. Fish Dis.. 8: $139-142$.

EWING, M.S.; S.A. EWING \& M.A. ZIMMER. 1982, Sublethal copper stress and susceptibility of channel catfish to experimental infections with Ichthyophthirius multifiliis. Bull. Environ. Control Toxicol. 28: 674-81. 
Kudo, R.R. 1966. Protozoology. Springfield, Charles C. Thomas, $5^{\text {th }}$ ed., p. 892-894.

MArtins, M.L.; V.N. Souza \& F.R. MorAes. 1999. Comparative evaluation of the susceptibility of cultivated fishes to the natural infection with Myxosporean parasites and tissue changes in the host. Rev. Brasil. Biol. 59 (2): 263-269.

McCAllum, H.I. 1986. Acquired resistance of black mollies Poecilia latipina to infection by Ichthyophthirius multifiliis. Parasitology 93: 251-261.

PYLE, S.W. \& D.L. DAWE. 1985, Stage-dependent protein composition in the life cycle of synchronous Ichthyophthirius multifiliis, a ciliate fish parasite. Jour. Protozool. 32 (2): 355-357.

Steel, R.G.D. \& J.H. TORRIE. 1980. Principles and Procedures of Statistics. Nova York, McGraw Hill, $2^{\text {nd }}$ ed., 633 p.

Recebido em 14.XI.2000; aceito em 24.VII. 2001. 